\title{
Are there candidates for high-dose chemotherapy in ovarian carcinoma?
}

\author{
Renaud Sabatier ${ }^{1,2^{*}}$, Anthony Gonçalves ${ }^{1,3,4}$, François Bertucci ${ }^{1,2,4}$, Maria-Antonietta Capiello ${ }^{1}$, Frédérique Rousseau ${ }^{1}$, \\ Eric Lambaudie ${ }^{5}$, Christian Chabannon ${ }^{4,6}$, Patrice Viens ${ }^{1,4}$ and Jean-Marc Extra ${ }^{1}$
}

\begin{abstract}
Background: Prognosis of advanced ovarian carcinomas (AOC) remains poor with a 5 -year survival of $30 \%$. Benefit from high-dose chemotherapy (HDC) in this disease has not been demonstrated to date.

Methods: To evaluate the value of HDC as consolidation treatment after surgery and platinum/taxane-based therapy, we designed a monocentric retrospective comparative study. We used a subset approach to identify parameters associated with HDC efficacy.

Results: One hundred and three AOC patients treated with conventional chemotherapy alone (CCA) were compared to 60 patients receiving HDC plus hematopoietic stem cell support. After a median follow-up of 47.5 months there was no overall survival (OS) advantage for the HDC group in the whole population $(p=0.29)$. Nevertheless, HDC was associated to a better outcome in young patients ( $\leq 50$ years), both in term of progression-free survival ( $p=0.02$, log-rank test) and OS ( $p=0.05$, log-rank test). Median OS was 54.6 and 36 months in the HDC and CCA groups, respectively.

Conclusions: Although randomized trials failed to demonstrate any benefit for HDC in AOC patients, this study suggests that young patients may derive a substantial advantage from receiving it after the standard treatment. Further prospective studies are warranted to confirm this gain and to search for the biological processes associated with this improvement.
\end{abstract}

Keywords: Ovarian carcinomas, Prognosis, High dose chemotherapy, Stem cell support

\section{Background}

Ovarian carcinoma is the first cause of death by gynecologic malignancy in western countries. In 2010 in USA, around 22000 cases were diagnosed and 14 000 deaths were reported [1]. Such a poor prognosis is due to late diagnosis and relative lack of efficacy of current treatments. The therapeutic sequence used by most of clinicians is maximal cytoreductive surgery (also called debulking surgery) followed by adjuvant chemotherapy for undifferentiated or advanced tumors [2-7]. Nevertheless, $20 \%$ of patients are initially refractory to this treatment and more than $50 \%$ of patients who are initially in complete remission will relapse and ultimately succumb

\footnotetext{
* Correspondence: sabatierr@ipc.unicancer.fr

'Department of Medical Oncology, Institut Paoli-Calmettes, $232 \mathrm{Bd}$

Ste-Marguerite, Marseille 13273, France

${ }^{2}$ Department of Molecular Oncology, Centre de Recherche en Cancérologie de Marseille, UMR1068 INSERM, Marseille, France

Full list of author information is available at the end of the article
}

from disease $[8,9]$. Consequently, overall survival is quite reduced and has remained stable since 20 years $(30-40 \%$ at five years for all stages). Early stages have a favorable prognosis $(\sim 90 \%)$, while life expectancy is only $30 \%$ after 5 years when disease is extended to peritoneal cavity and only $5-10 \%$ when there is distant metastasis $[8,9]$.

A combination of a platinum agent and paclitaxel is the standard therapy with benefits in terms of response, progression-free and overall survivals, leading in stages III and IV to a median survival of more than 35 months $[10,11]$. Several laboratory models [12] as well as retrospective analyses of clinical studies $[13,14]$ have strongly suggested that chemotherapy dose could favorably influence ovarian cancer outcome. Major chemotherapy dose intensification using alkylating agents with autologous hematopoietic stem cell support (HSCS) has been investigated in this setting, with encouraging results in pilot studies [15-18]. However, these promising results have

\section{Biomed Central}

(c) 2012 Sabatier et al.; licensee BioMed Central Ltd. This is an Open Access article distributed under the terms of the Creative Commons Attribution License (http://creativecommons.org/licenses/by/2.0), which permits unrestricted use, distribution, and reproduction in any medium, provided the original work is properly cited. 
not been confirmed in randomized phase III trials $[19,20]$, and high-dose chemotherapy (HDC) is currently not recommended for advanced ovarian carcinomas (AOC).

Nevertheless, ovarian cancer is clinically heterogeneous. Patients with morphologically similar, advancedstage tumors display a broad range of clinical outcomes. Features currently used for prognosis and chemotherapy decision are clinicopathological and include patient's age, performance status, FIGO stage, histological tumor grade and subtype, initial surgery results and response to chemotherapy. These factors were not incorporated in the initial design of randomized studies although they might be associated with different responses to HDC.

The present study is a retrospective comparative survival analysis, including subsets analysis based on usual clinicopathological features. A survival comparison was done between 103 patients with AOC treated by surgery plus platinum/taxane-based conventional chemotherapy alone (CCA) and 60 patients who received the same treatment plus HDC and autologous HSCS.

\section{Methods}

\section{Population description}

Patients were selected in our institutional "Ovarian Cancer" database, which included all ovarian cancer patients treated at the Institut Paoli-Calmettes (Marseilles, France) since 1995. Eligible patients were aged between 18 and 64 years and had histologically proven invasive ovarian carcinoma with advanced (FIGO stage IIIc) or metastatic (FIGO stage IV) disease at diagnosis.

All patients were treated using a standard multimodal approach including surgery and platinum/taxane-based chemotherapy. In the "HDC" group, patients also received HDC with HSCS. Hematological rescue consisted of autologous hematopoietic stem cells collected from peripheral blood.

After completion of treatment, patients were evaluated at 3-month intervals for the first 2 years and at 6-month intervals thereafter. Evaluations included clinical examination and blood tests with CA125 assessment. CT scan evaluations were performed every 6 months for the first 5 years and yearly thereafter. Other examinations were performed only when indicated.

The study was approved by our institutional review board. According to the French law, since it was a retrospective study without biological research and without therapy modification, no personal consent was required.

\section{Statistical analysis}

Differences in patient characteristics between the two chemotherapy groups (with $v s$. without HDC) were tested by the Fisher's exact test (categorical variables) or the Student's $t$-test (continuous variables). Tested parameters were age at diagnosis (with a threshold at 50 years old), performance status, FIGO stage, histological subtype (serous $v s$. others), histological grade according to Silverberg classification (grade 1 and 2 were pooled), presence of residual disease after surgery, presence of a clinical remission after platinum/taxane-based therapy (according to clinical and radiological examinations), CA125 normalization after platinum/taxane-based therapy.

Progression-free survival (PFS) was calculated from the date of diagnosis until date of first disease progression. Overall survival (OS) was calculated from the date of diagnosis until date of death of any cause. Follow-up was measured from the date of diagnosis to the date of last news for live patients. Data concerning patients without disease progression or death at last follow-up were censored. Survival curves were estimated using the Kaplan-Meier method, and compared with the log-rank test. The prognostic impact of above-cited factors and chemotherapy regimen was assessed by the Cox regression method both in univariate and multivariate analysis. Multivariate analyses only included variables with pvalue lower than $5 \%$ in univariate analysis. All statistical tests were two-sided at the $5 \%$ level of significance. Statistical analyses were performed using SPSS software (version 16.0).

\section{Results}

\section{Patients and treatment}

One hundred sixty-three patients with advanced ovarian carcinomas treated at our institution between April 1995 and July 2009 were included in this study. Tumor characteristics are listed in Table 1. Median age at diagnosis was 54 years (standard deviation, 8.7 years) and $68 \%$ were older than 50 years. Fifty three percent were grade II serous tumors. Complete cytoreductive surgery could not be achieved for $41 \%$ of patients. Seventy percent presented no clinical residual disease after conventional treatment including surgery and chemotherapy. All patients received a platinum/taxane-based chemotherapy. Ninety percent of patients received carboplatin, $10 \%$ cisplatin, $79 \%$ paclitaxel and 21\% docetaxel. Carboplatin was given every three weeks, according to the Calvert's formula with an area under curve of 6 before and 5 after January 2005. Cisplatin was given every three weeks at a dose of $75 \mathrm{mg} / \mathrm{m}^{2}$. Paclitaxel was administered every three weeks at the dose of $175 \mathrm{mg} / \mathrm{m}^{2}$ until 2008, and then weekly at the dose of $80 \mathrm{mg} / \mathrm{m}^{2}$. Docetaxel was given with a 3-weeks frequency, at the dose of $75 \mathrm{mg} / \mathrm{m}^{2}$. Patients received a median of 6 cycles, with a minimum of 1 , and a maximum of 8 cycles.

Seventy-one patients underwent second look surgery after platinum/taxane-based chemotherapy. Of them, 25 presented a pathological complete response. Eighteen percent did not reach CA125 normalization after 
Table 1 Clinicopathological features of advanced ovarian carcinomas with and without high-dose chemotherapy

\begin{tabular}{|c|c|c|c|c|c|c|}
\hline & \multirow[t]{2}{*}{$\mathbf{N}$} & & $\frac{\mathrm{CCA}}{\mathrm{N}(\%)}$ & $\frac{\mathrm{HDC}}{\mathrm{N}(\%)}$ & \multirow[t]{2}{*}{ p -value } & \multirow[t]{2}{*}{ Odd or Hazard Ratio $(95 \mathrm{Cl})$} \\
\hline & & & 103 & 60 & & \\
\hline Follow-up (median, months) & 163 & & 46.7 & 48.2 & $0.08^{* * *}$ & \\
\hline Median Age (years) & 163 & & 56,0 & 53,00 & $09^{* * *}$ & \\
\hline \multirow[t]{3}{*}{ Age } & 163 & & & & $0.73^{* * * *}$ & $1.15[0.55-2.45]$ \\
\hline & & $\leq 50 y$ & $34(33)$ & $18(30)$ & & \\
\hline & & $>50 y$ & $69(67)$ & $42(70)$ & & \\
\hline \multirow[t]{3}{*}{ OMS } & 117 & & & & $0.17^{* * * *}$ & $0.35[0.06-1.37]$ \\
\hline & & $0-1$ & $63(81)$ & $36(92)$ & & \\
\hline & & $2-3$ & $15(19)$ & $3(8)$ & & \\
\hline \multirow[t]{3}{*}{$\mathrm{FIGO}$} & 163 & & & & $0.33^{* * * *}$ & $1.47[0.63-3.39]$ \\
\hline & & IIIC & $84(82)$ & $45(75)$ & & \\
\hline & & IV & $19(18)$ & $15(25)$ & & \\
\hline \multirow[t]{3}{*}{ Histological subtype } & 163 & & & & $0.62^{* * * *}$ & $0.82[0.40-1.65]$ \\
\hline & & Serous & $62(60)$ & $39(65)$ & & \\
\hline & & Others & $41(40)$ & $21(35)$ & & \\
\hline \multirow[t]{3}{*}{ Grade } & 98 & & & & $0.01^{* * * *}$ & $0.32[0.12-0.81]$ \\
\hline & & $1-2$ & $19(31)$ & $21(58)$ & & \\
\hline & & 3 & $43(69)$ & $15(42)$ & & \\
\hline \multirow[t]{3}{*}{ Cytoreductive surgery } & 160 & & & & & \\
\hline & & Complete & $56(56)$ & $40(67)$ & $0.24^{* * * *}$ & $0.64[0.31-1.30]$ \\
\hline & & residual disease & $44(44)$ & $20(33)$ & & \\
\hline \multirow[t]{3}{*}{ Clinical complete response* } & 161 & & & & & \\
\hline & & Yes & $63(62)$ & $50(83)$ & $0.007^{* * * *}$ & $0.33[0.14-0.77]$ \\
\hline & & No & $38(38)$ & $10(17)$ & & \\
\hline \multirow[t]{3}{*}{ CA- $125^{* *}$} & 149 & & & & $0.66^{* * * *}$ & $0.75[0.27-1.92]$ \\
\hline & & Normal & $73(80)$ & $49(85)$ & & \\
\hline & & $>$ Normal & $18(20)$ & $9(15)$ & & \\
\hline $\begin{array}{l}\text { Time from end of initial } C T \text { to } \\
\mathrm{HDCT} \text { (median, months) }\end{array}$ & 61 & & NA & 2.8 & NA & NA \\
\hline Median PFS (months) & & & 18.1 & 20.1 & $0.09^{* * * * *}$ & \\
\hline Median OS (months) & & & 41.3 & 47.3 & $0.24^{* * * * *}$ & \\
\hline
\end{tabular}

$C C A$, conventional chemotherapy alone; $H D C$, high-dose chemotherapy; $N$, number of cases with data available; $95 C l$, $95 \%$ confidence interval; OMS, performance status; NA, not asssessable; PFS, progression-free survival; OS, overall survival. *Clinical and radiological complete response after platinum and taxane-based chemotherapy; ${ }^{* *}$, CA-125 rate after platinum and taxane-based chemotherapy; ${ }^{* * *}, T$-test; ${ }^{* * *}$, Fisher's exact test; ${ }^{* * * *}$, Log-rank test.

standard treatment achievement. Median PFS of the whole population was 18.8 months, with a 5 -year PFS of 25.4\%. Median OS was 42.7 months, with a 5 -year OS of $32.6 \%$ (Figure 1).

Out of these 163 patients, two groups were distinguished with respect to the regimen of chemotherapy: 103 patients (63\%) received conventional chemotherapy alone ("CCA group") and 60 patients (37\%) received HDC with HSCS after completion of a platinum/ taxane-based regimen ("HDC group"). Median time from platinum/taxane-based chemotherapy completion to HDC was 2.8 months. Because of the large period of inclusion, HDC regimens were heterogeneous. Nevertheless, all patients received alkylating agents. The details of the HDC regimen are noted in Table 2. Median and mean numbers of re-injected hematopoietic stem cells (CD34 positive cells) per patient were 6.1 million and 8.3 million per $\mathrm{Kg}$, respectively.

There was no statistically significant difference between the two subsets (Table 1), except for clinical complete remission after platinum/taxane-based regimen: $62 \%$ in the CCA group versus $83 \%$ in the HDC 


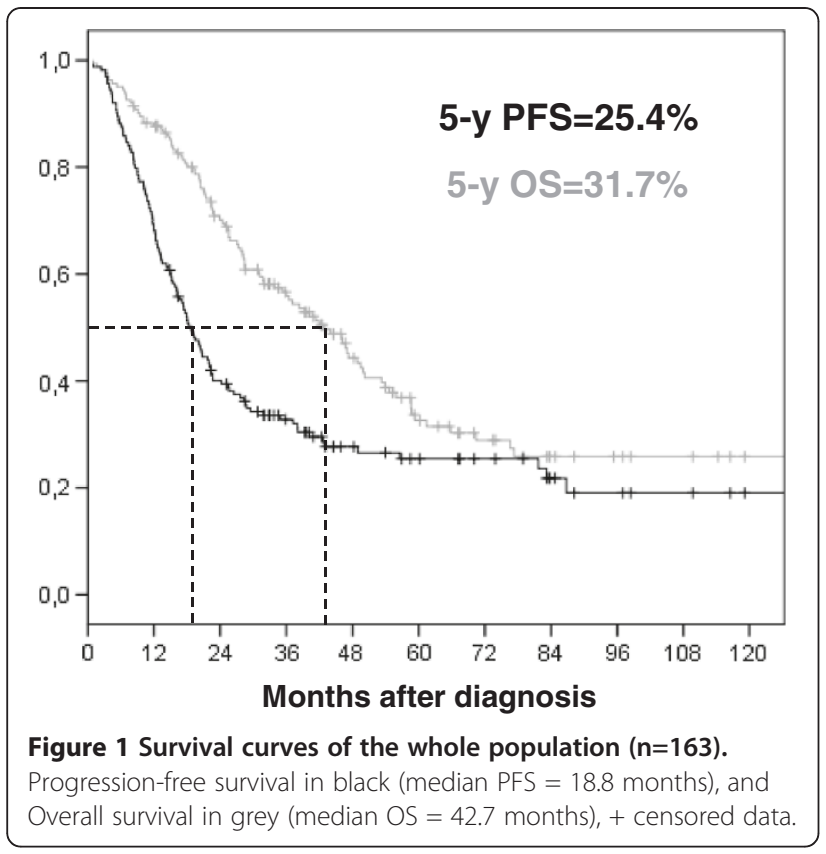

group ( $p=7.0 \mathrm{E}-03$, Fisher's exact test). Such an imbalance can be explained by the fact that only patients with complete or at least partial response were candidate to HDC. It is of note that no toxic death was observed in the HDC arm.

\section{Pathological response}

Seventy-one patients underwent second look surgery (SLS) at the end of the platinum/taxane-based treatment. Among them, 27 received HDC after SLS. There was no statistical difference in pathological response between the HDC and the CCA subsets: seven pathological complete responses were observed in the HDC subset (26\%) and eighteen in the CCA group (41\%), $p=0.31$ (Fisher's exact test).

Table 2 High dose chemotherapy regimen in the high-dose chemotherapy group $(\mathrm{N}=60)$

\begin{tabular}{ll}
\hline & N (\%) \\
\hline Carboplatin AUC 18 & $12(20)$ \\
$\begin{array}{l}\text { Cyclophosphamide } 60 \mathrm{mg} / \mathrm{kg} / \mathrm{d}(\mathrm{d}-3 \text { to } \mathrm{d}-2)+ \\
\text { melphalan } 140 \mathrm{mg} / \mathrm{m}^{2} \mathrm{~d}-1\end{array}$ & $32(53)$ \\
$\begin{array}{l}\text { Cycle 1: cyclophosphamide } 60 \mathrm{mg} / \mathrm{kg} / \mathrm{d}(\mathrm{d}-3 \text { to } \mathrm{d}-2)+ \\
\text { melphalan } 140 \mathrm{mg} / \mathrm{m}^{2} \mathrm{~d}-1+\end{array}$ & 8 (13) \\
Cycle 2: thiotepa $300 \mathrm{mg} / \mathrm{m}^{2} / \mathrm{d} \mathrm{d}-3$ to $\mathrm{d}-2$ & $3(5)$ \\
Melphalan $140 \mathrm{mg} / \mathrm{m}^{2} \mathrm{~d}-1$ & $1(2)$ \\
Thiotepa $300 \mathrm{mg} / \mathrm{m}^{2} / \mathrm{d} \mathrm{d}-3$ to d-2 & $2(3)$ \\
Cycle 1: melphalan $140 \mathrm{mg} / \mathrm{m}^{2} \mathrm{~d}-1+$ & \\
Cycle 2: thiotepa $300 \mathrm{mg} / \mathrm{m}^{2} / \mathrm{d} \mathrm{d}-3$ to d-2 & $2(3)^{*}$ \\
Topotecan $7,5 \mathrm{mg} / \mathrm{m}^{2} / \mathrm{d}(\mathrm{d}-6$ to d-2)
\end{tabular}

$N$, number of patients; $A U C$, area under curve; $d$, day; ${ }^{*}$, patients treated in the ITOV 01 trial.

\section{Outcome and survival}

Median follow-up was 47.5 months. There were 79 disease progressions and 64 deaths in the conventional therapy group versus 40 and 35, respectively in the HDC group. Outcome evaluation according to therapy showed that median PFS and OS were similar with 20.1 and 47.3 months in the HDC group versus 18.1 and 41.3 months in the CCA group, respectively.

\section{Prognostic parameters}

In the whole population (Table 3A), PFS was influenced by debulking surgery results (hazard ratio (HR) for progression of 0.38 if no residual disease was present), response to therapy ( $\mathrm{HR}=0.33$ in case of complete clinical response $(\mathrm{CCR}))$, and CA125 normalization $(\mathrm{HR}=0.45)$. Outcome was not significantly improved when HDC was added (PFS, $p=0.09$; OS, $p=0.24$ ), (Figure 2). Multivariate analysis showed that only two features had an independent prognostic value in the whole population: surgical results and clinical response to initial chemotherapy.

We then explored the prognostic value of the usual clinicopathological features in each treatment arm.

We first examined PFS. In the CCA group, PFS was influenced by debulking surgery results $(\mathrm{HR}=0.29)$, clinical response to therapy $(\mathrm{HR}=0.32)$, and CA125 normalization $(\mathrm{HR}=0.32)$. In the $\mathrm{HDC}$ arm, age $(\mathrm{HR}=2.07$ if older than 50 years) FIGO stage (HR=0.41 for stage IIIc) and clinical response to initial treatment $(H R=0.46)$ had a prognostic value (Table 3B). When focusing only in the pre-treatment clinicopathological features, only age and FIGO stage had a prognostic value in the HDC group.

Impact of HDC on PFS according to these last two features was analyzed. HDC significantly improved PFS in young patients $(p=0.02, \log$-rank test), but had no prognostic value in women older than 50 years $(p=0.81$, log-rank test), (Figure 3). In the same way, HDC increased PFS in stage IIIc patients $(p=0.03$, log-rank test), but not in stage IV cases ( $p=0.94$, log-rank test).

Cox regression analyses performed in both young patients and stage IIIc cases found that PFS was significantly affected by HDC, surgical results, complete remission and Ca125 normalization after conventional treatment. Young patients had a 2.44-fold rate of progression if they did not receive HDC (Table 4); and stage IIIc patients a 1.61 -fold rate of progression if they did not receive HDC (Additional file 1: Table S1). By multivariate analyses HDC had an independent prognostic value in young patients (Table 4), but not in stage IIIc cases (Additional file 1: Table S1).

We then explored the impact of chemotherapy regimen on OS according to the two factors independently associated with a PFS improvement induced by HDC (young age and FIGO stage IIIc). We could observe that 
Table 3 Prognostic parameters (PFS), Cox regression analysis

\begin{tabular}{|c|c|c|c|c|c|c|c|c|}
\hline \multicolumn{9}{|l|}{ A. Whole population } \\
\hline & \multicolumn{4}{|c|}{ Univariate analysis } & \multicolumn{4}{|c|}{ Multivariate analysis } \\
\hline & $\mathbf{N}$ & $\mathrm{HR}$ & $95 \mathrm{Cl}$ & p -value & $\mathbf{N}$ & HR & $95 \mathrm{Cl}$ & p -value \\
\hline Age (>50y vs $\leq 50 y)$ & 163 & 1.12 & $0.76-1.66$ & 0.57 & & & & \\
\hline OMS (0-1 vs 2-3) & 117 & 1.53 & $0.88-2.67$ & 0.14 & & & & \\
\hline FIGO (IIIC vs IV) & 163 & 0.7 & $0.45-1.08$ & 0.1 & & & & \\
\hline Histology (serous vs others) & 163 & 0.95 & $0.66-1.39$ & 0.8 & & & & \\
\hline Grade (1-2 vs 3) & 98 & 1.2 & $0.93-1.55$ & 0.16 & & & & \\
\hline Serous grade 3 (vs others) & 98 & 1.42 & $0.80-2.52$ & 0.23 & & & & \\
\hline Surgery (complete vs non complete) & 160 & 0.38 & $0.26-0.54$ & $2.23 \mathrm{E}-07$ & 147 & 0.57 & $0.37-0.87$ & 0.01 \\
\hline Complete clinical remission (Yes vs No) & 161 & 0.33 & $0.23-0.49$ & $2.14 \mathrm{E}-08$ & 147 & 0.55 & $0.33-0.92$ & 0.02 \\
\hline CA-125 (normal vs >normal) & 149 & 0.45 & $0.29-0.71$ & $6.9 \mathrm{E}-04$ & 147 & 0.77 & $0.45-1.32$ & 0.34 \\
\hline Time from end of initial CT to HDC & & & NA & & & & & \\
\hline Treatment (CCA vs HDC) & 163 & 1.39 & 0.95-2.03 & 0.09 & & & & \\
\hline \multicolumn{9}{|c|}{ B. According to chemotheraphy regimen, univariate analysis } \\
\hline & \multicolumn{4}{|c|}{ Conventional CT } & \multicolumn{4}{|c|}{ High dose $\mathrm{CT}$} \\
\hline & $\mathbf{N}$ & HR & $95 \mathrm{Cl}$ & p-value & $\mathbf{N}$ & HR & $95 \mathrm{Cl}$ & p -value \\
\hline Age (>50y vs $\leq 50 y)$ & 103 & 0.83 & $0.52-1.33$ & 0.44 & 60 & 2.03 & $0.96-4.29$ & 0.06 \\
\hline OMS (0-1 vs 2-3) & 78 & 1.56 & $0.84-2.89$ & 0.16 & 39 & 0.96 & $0.22-4.17$ & 0.95 \\
\hline FIGO (IIIC vs IV) & 103 & 0.93 & $0.52-1.70$ & 0.82 & 60 & 0.4 & $0.20-0.78$ & 0.007 \\
\hline Histology (serous vs others) & 103 & 1.24 & $0.78-1.97$ & 0.37 & 60 & 0.83 & $0.44-1.58$ & 0.56 \\
\hline Grade (1-2 vs 3) & 62 & 1.17 & $0.85-1.61$ & 0.35 & 36 & 1.08 & $0.67-1.72$ & 0.76 \\
\hline Serous grade 3 (vs others) & 62 & 0.81 & $0.57-1.15$ & 0.24 & 36 & 0.98 & $0.51-1.87$ & 0.94 \\
\hline Surgery (complete vs non complete) & 100 & 0.29 & $0.18-0.46$ & $2.2 \mathrm{E}-07$ & 60 & 0.65 & $0.34-1.22$ & 0.18 \\
\hline Complete clinical remission (Yes vs No) & 101 & 0.32 & $0.20-0.51$ & $1.78 \mathrm{E}-06$ & 60 & 0.44 & $0.20-0.97$ & 0.04 \\
\hline CA-125 (normal vs >normal) & 91 & 0.32 & $0.18-0.56$ & $6.41 \mathrm{E}-05$ & 58 & 1.21 & 0.53 & 2.74 \\
\hline Time from end of initial CT to HDC & & & NA & & 60 & 0.97 & $0.86-1.09$ & 0.59 \\
\hline Treatment (CCA vs HDC) & & & NA & & & & NA & \\
\hline
\end{tabular}

PFS, progression-free survival; $N$, number of cases with data available; $95 \mathrm{Cl}$, 95\% confidence interval; $H R$, hazard ratio; OMS, performance status; $H D C$, high-dose chemotherapy; CCA, conventional chemotherapy alone.

HDC plus HSCS significantly improved survival only when age was under 50 years, but not in stage IIIc patients (Figure 4). Median overall survival was highly increased in young patients treated with HDC (54.6 months) when compared to conventional therapy alone (36 months), ( $p=0.05)$. Effect of HDC according to FIGO stage IIIc was less important and non significant: median OS was 53.9 months in the HDC subset versus 41.3 months in the CCA subset $(p=0.11)$.

It is worth to note that the prognostic value of HDC was not modified by the initial response to treatment. HDC improved survival in young patients whatever the response to initial therapy was: median PFS was 5 months for CCA vs. 15 months for HDC in patients with residual disease after treatment; and 38 months for CCA whereas it had not been reached after a follow-up of 47 months in the HDC group for cases with initial CCR and CA-125 normalization.

\section{Discussion}

Even though HDC plus HSCS cannot be considered as a standard of care for all AOC patients, results from this monocentric comparative retrospective study including 163 patients suggest that it may be beneficial to young patients. In women under 50 years of age, addition of HDC to platinum/taxane-based chemotherapy improves not only PFS $(p=0.02$ ), but also OS (median of 54.6 months versus 36 months with conventional therapy alone, $p=0.05$ ).

Despite advances in chemotherapy and multidisciplinary management of ovarian carcinomas, the prognosis of patients with advanced stages (FIGO III/IV) remains poor. Median PFS and OS of our cohort treated with a platinum/taxane combination alone (18.1 and 41.3 months, respectively) were similar to those of phase III pivotal studies: 18 and 38 months [10], and 19.4 and 48.7 months [6] with cisplatin and paclitaxel; 20.7 and 

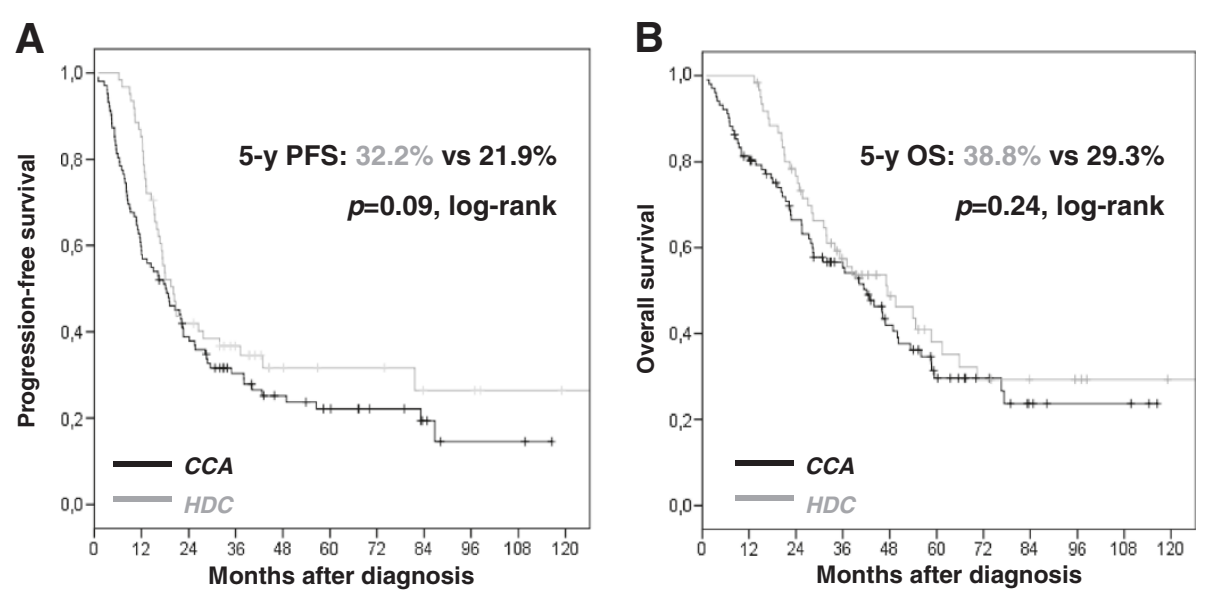

Figure 2 Progression-Free Survival (A) and Overall Survival (B) according to chemotherapy regimen in the whole population. Conventional chemotherapy alone (CCA) alone in black, $n=103$; conventional chemotherapy plus high-dose chemotherapy in grey, $n=60,+$ censored data.

57.4 months for carboplatin and paclitaxel [6]. Our population was thus similar to previously described cohorts. Prognosis is known to be dramatically influenced by cytoreductive surgery and response to adjuvant platinum/taxane-based chemotherapy. However, even good responders to initial treatment often have a poor prognosis due to secondary relapse. Such relapses are generally chemoresistant and remain the major cause of death. Thus, it may be useful to treat chemosensitive patients in order to kill residual clones and avoid the chemoresistant relapse. Different consolidation therapies have been considered: conventional maintenance chemotherapy, intraperitoneal treatment with chemotherapy and/or hyperthermia, and HDC with HSCS. The latter has been widely used in the context of poor risk hematological malignancies and sometimes in chemosensitive solid tumors such as metastatic breast cancer [21-25] or germ cell tumors [26] with controversial results.

The main toxicity of high-dose alkylating agents is hematological. Stem cell transplantation is needed in such treatment strategies to limit the duration and consequences of aplasia. Nevertheless, severe infection can always occur during grade 4 neutropenia and remains the major potential risk during severe aplasia. However we observed no toxic death after HDC in this study.

Several promising but preliminary studies have reported that HDS plus HSCS may improve ovarian cancer outcome in first-line therapy. These results were observed when HDC was used either as front-line treatment $[19,27]$, or as consolidation therapy [17,28-32]. However published randomized phase III trials did not confirm these results. In a single center small-sized study from Papadimitriou et al. [19], although PFS was
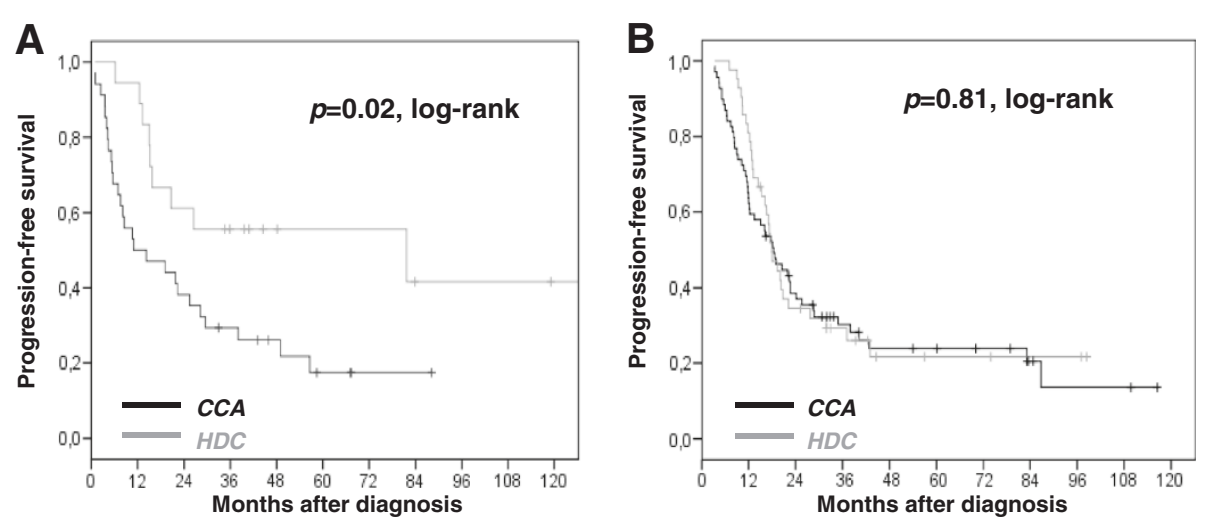

Figure 3 Progression-Free Survival according to chemotherapy regimen. Conventional chemotherapy alone (CCA) in black or plus highdose chemotherapy (HDC) in grey. (A) In patients under 50 years of age $(n=52)$, median PFS was 11 months in the CCA subset versus 81.7 months in the HDC subset. (B) In patients older than 50 years old $(n=111)$, median PFS was 18.3 months in the CCA subset versus 17.9 months in the HDC subset. + censored data. 
Table 4 Prognostic features (PFS) in young patients ( $\leq 50$ years), Cox regression analyses

\begin{tabular}{|c|c|c|c|c|c|c|c|c|}
\hline & \multicolumn{4}{|c|}{ Univariate analysis } & \multicolumn{4}{|c|}{ Multivariate analysis } \\
\hline & $\mathrm{N}$ & HR & $95 \mathrm{Cl}$ & $p$-value & $\mathrm{N}$ & $\mathrm{HR}$ & $95 \mathrm{Cl}$ & $p$-value \\
\hline OMS (0-1 vs 2-3) & 36 & 1.76 & $0.71-4.38$ & 0.22 & & & & \\
\hline FIGO (IIIC vs IV) & 52 & 0.57 & $0.25-1.33$ & 0.19 & & & & \\
\hline Histology (serous vs others) & 52 & 0.81 & $0.51-1.56$ & 0.52 & & & & \\
\hline Grade (1-2 vs 3) & 31 & 1.31 & $0.83-2.08$ & 0.25 & & & & \\
\hline Serous grade 3 (vs others) & 31 & 1.06 & $0.59-1.88$ & 0.85 & & & & \\
\hline Surgery (complete vs non complete) & 52 & 0.29 & $0.15-.058$ & $4.97 \mathrm{E}-07$ & 51 & 0.43 & $0.19-0.94$ & 0.034 \\
\hline Complete clinical remission (Yes vs No) & 51 & 0.22 & $0.11-0.45$ & $3.65 \mathrm{E}-05$ & 51 & 0.33 & $0.15-0.74$ & 0.007 \\
\hline CA-125 (normal vs >normal) & 44 & 1.87 & $0.84-4.16$ & 0.12 & & & & \\
\hline Treatment (CCA vs HDC) & 52 & 2.44 & $1.14-5.25$ & 0.02 & 51 & 2.31 & $1.06-5.04$ & 0.036 \\
\hline
\end{tabular}

PFS, progression-free survival; $N$, number of cases with data available; $95 \mathrm{Cl}, 95 \%$ confidence interval; $H R$, hazard ratio; OMS, performance status; $C C A$, conventional chemotherapy alone; $H D C$, high-dose chemotherapy.

numerically improved by HDC (85.2 months versus 18 months), the difference was not significant ( $p=0.059)$. Moreover, no significant difference was observed in OS (not reached after 75 months of follow-up versus 75 months, $\mathrm{p}=0.38$ ). The authors attributed PFS gain to the higher rates of stages IV (14\% vs. $8.1 \%)$ and larger postoperative residue $(32.6 \%$ vs. $21.6 \%)$ in the conventional therapy arm. Mobus et al. reported similar findings in their relatively large phase III trial published in 2007 [20]. Median PFS was 29.5 months in the HDC arm versus 20.5 in the control arm $(\mathrm{p}=0.40)$. There was also no difference regarding OS (54.4 vs. 62.8 months, $p=0.54$ ). Conclusions of these studies were that HDC does not improve outcome in advanced ovarian cancer.

Nevertheless a question that could be asked is: are these conclusions relevant for all patients or is there a subset of patients who may benefit from HDC? In this retrospective study, we tried to address this issue using a subgroup analysis approach in a large population of more than 160 patients. We have explored prognostic value of the different histoclinical features used in ovarian cancer evaluation: age, performance status, FIGO stage, histological subtype, histological grade, debulking status and response to conventional chemotherapy. Age was the only parameter correlated to HDC efficacy, both in PFS and OS. Intriguingly, patients under 50 years of age had a gain in survival when HDC was performed after platinum/taxane-based chemotherapy: median OS of 54.6 months vs. 36 months with standard treatment $(p=0.05)$. This benefit was observed independently of the response after standard treatment. A possible hypothesis is that, in young patients known to have a better prognosis than older women, HDC may be more efficient regardless of the persistence of residual disease after conventional therapy. A hypothesis to explain these results could be the higher prevalence of $B R C A$-related tumors in younger patients compared to sporadic forms [33,34]. Indeed, BRCA-related ovarian cancers display distinctive biological and clinical characteristics including genomic instability, dysfunction in DNA repair processes especially homologous recombination and thereby higher sensitivity to platinum-based
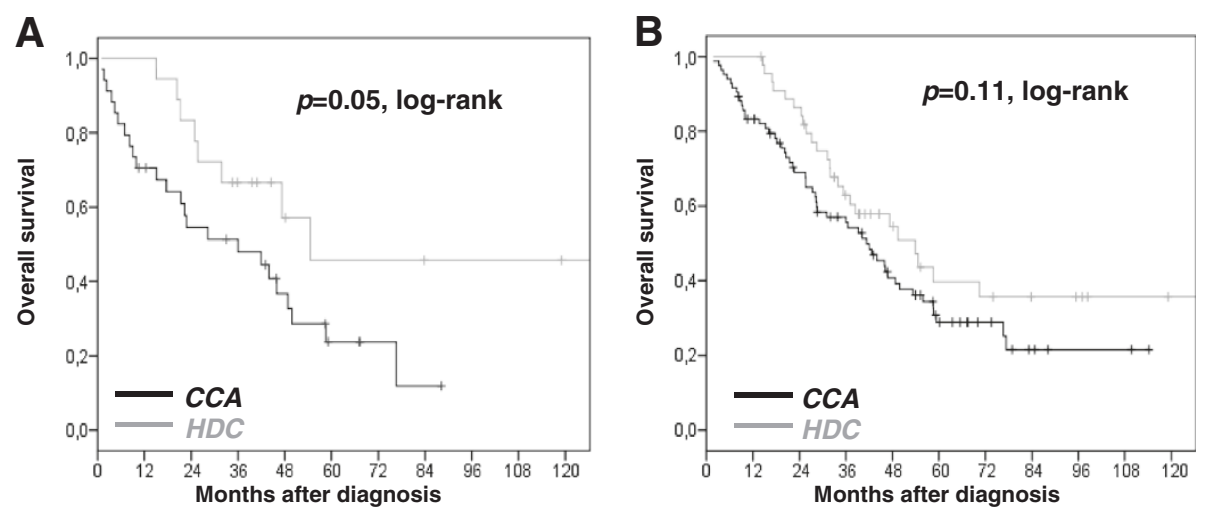

Figure 4 Overall survival after conventional chemotherapy alone (black) or plus high dose chemotherapy (grey). (A) In patients under 50 years of age $(n=52)$ median OS was 36 months in the CCA subset versus 54.6 months in the HDC subset; (B) in stage IIIc cases ( $n=129)$ median OS was 42 months in the CCA subset versus 49.5 months in the HDC subset; + censored data. 
chemotherapy and better outcome [35,36]. Of note, recent data have shown that this phenotype could be extended to a larger group of tumors without germline $B R C A$ mutations, the so-called "BRCAness" phenotype $[37,38]$. Thus, the benefit of alkylating agents-based HDC in younger patients observed in this study may reflect the enrichment in BRCA-related or BRCAnessassociated forms in this subgroup and therefore a higher sensitivity of ovarian cancer cells to DNA damages that can be induced by alkylating agents. As suggested by the dose-effect concept, more chemotherapy -and thus more DNA lesions- may lead to an increase in tumor cells death.

A similar exploitation of this Achilles' heel of the BRCAness-related phenotype was recently demonstrated with the new therapeutic class of PARP1 inhibitors [39], which also target DNA repair processes. PARP1 inhibitors are able to induce DNA single-strand breaks that will accumulate and degenerate to DNA double-strand breaks, which are not appropriately repaired if the BRCA pathway is deficient or dysfunctional, the so-called synthetic lethality concept. Olaparib has been shown to induce relevant and promising rates of response when used as single agent in AOC. Interestingly, its activity was documented not only in patients carrying $B R C A$ mutations [40,41], but also in patients without constitutive mutations [42], further validating the BRCAness concept.

This phenomenon may be increased with the association of PARP inhibitor and alkylating drugs. Such an additive activity may not be necessary in case of complete remission after standard treatment, but may have a positive effect when the tumor burden has been decreased but not eliminated by the initial treatment.

Our observations show that more treatment may be more effective in young patients. Addition of HDC after platinum/taxane-based chemotherapy in this population should be compared to other ways to enhance treatment exposure. Intra-peritoneal chemotherapy may be an option to increase the doses of platinum and/or taxane administered to cancer cells, with less hematological adverse events [43]. Another issue is the lack of studies comparing consolidation (such as HDC) and maintenance therapy, which could be based on cytotoxic treatments [44] as well as angiogenesis inhibitors [45]. Nevertheless it is of note that, except angiogenesis inhibiting agents, none of the treatments cited above has shown his superiority in randomized trials versus observation alone, but without age consideration as we have done in this analysis. These new findings must be balanced with the fact that this study was retrospective, and that HDC regimens were heterogeneous. Nevertheless, despite its retrospective nature, this study, based on a large population, used a comparative design and included subgroup analyses with traditional clinical and pathological prognostic factors. Another limitation of this work is the absence of relevant information about the $B R C A$ status of our patients. Unfortunately, this data was available only for few patients in our retrospective cohort (21 of 163), with only six BRCA1 and two BRCA2 mutations identified.

\section{Conclusions}

We have shown in this retrospective comparative study including more than 160 women, that, when applied to all patients, HDC does not improve advanced ovarian cancer survival. However, HDC seems to benefit to young patients (less than 50 years of age). Median overall survival in this subset presented an improvement of 18 months when HDC was performed after initial platinum/ taxane-based chemotherapy versus standard chemotherapy alone. This work is the first to make the hypothesis of a differential benefit from HDC according to age. As we know that young patients have a higher frequency of BRCA alterations than older women, they may have a more important benefit from HDC. That may lead to new clinical trials to explore this hypothesis of HDC usefulness in young patients, without or with combination with drugs targeting DNA repair such as olaparib.

\section{Additional file}

Additional file 1: Table S1. Prognostic parameters (PFS) in stage IIIC patients, Cox regression analyses.

\section{Abbrevations}

AOC: Advanced ovarian carcinoma; CCA: Conventional chemotherapy alone; CCR: Clinical complete response; HDC: High-dose chemotherapy; HR: Hazard ratio; HSCS: Hematopoietic stem cell support; OS: Overall survival; PFS: Progression-free survival; SLS: Second look surgery.

\section{Competing interests}

The authors declare that they have no competing interests.

\section{Authors' contributions}

Conception and design: RS. Acquisition of data: RS, AG, MAC, FR, EL, CC, PV, JME. Statistical analysis: RS. Manuscript writing: RS, AG, FB, JME. Final approval: all authors.

\section{Acknowledgements}

We would to thank Dr Jessica Moretta for her help in collecting data concerning BRCA genes mutations.

\section{Author details}

${ }^{1}$ Department of Medical Oncology, Institut Paoli-Calmettes, 232 Bd Ste-Marguerite, Marseille 13273, France. ${ }^{2}$ Department of Molecular Oncology, Centre de Recherche en Cancérologie de Marseille, UMR1068 INSERM, Marseille, France. ${ }^{3}$ Department of Molecular Pharmacology, Centre de Recherche en Cancérologie de Marseille, UMR1068 INSERM, Marseille, France. ${ }^{4}$ UFR Medicine, University of Mediterranean, Marseille, France. ${ }^{5}$ Department of Surgical Oncology, Institut Paoli-Calmettes, Marseille, France. ${ }^{6}$ Department of Hematology, Institut Paoli-Calmettes, Marseille, France.

Received: 20 August 2012 Accepted: 10 October 2012

Published: 16 October 2012 
References

1. National Cancer Institute. http://www.cancer.gov/cancertopics/types/ovarian

2. Cannistra SA: Cancer of the ovary. N Engl J Med 2006, 354:77-79.

3. du Bois A, Quinn M, Thigpen T, Vermorken J, Avall-Lundqvist E, Bookman M, et al: 2004 consensus statements on the management of ovarian cancer: final document of the 3rd International gynecologic cancer intergroup ovarian cancer consensus conference (GCIG OCCC 2004). Ann Oncol 2005, 17:93-96.

4. Bristow RE, Tomacruz RS, Armstrong DK, Trimble EL, Montz FJ: Survival effect of maximal cytoreductive surgery for advanced ovarian carcinoma during the platinum era: a meta-analysis. J Clin Oncol 2002, 20:1248-1259.

5. International Collaborative Ovarian Neoplasm Group: Paclitaxel plus carboplatin versus standard chemotherapy with either single-agent carboplatin or cyclophosphamide, doxorubicin, and cisplatin in women with ovarian cancer: the ICON3 randomised trial. Lancet 2002 360:505-515.

6. Ozols RF, Bundy BN, Greer BE, Fowler JM, Clarke-Pearson D, Burger RA, et al: Phase III trial of carboplatin and paclitaxel compared with cisplatin and paclitaxel in patients with optimally resected stage III ovarian cancer: a gynecologic oncology group study. J Clin Oncol 2003, 21:3194-3200.

7. Young RC: Early-stage ovarian cancer: to treat or not to treat. $J$ Natl Cancer Inst 2003, 95:94-95.

8. Holschneider $\mathrm{CH}$, Berek JS: Ovarian cancer: epidemiology, biology, and prognostic factors. Semin Surg Oncol 2000, 19:3-10.

9. McGuire WP, Brady MF, Ozols RF: The gynecologic oncology group experience in ovarian cancer. Ann Oncol 1999, 10(Suppl 1):29-34.

10. McGuire WP, Hoskins WJ, Brady MF, Kucera PR, Partridge EE, Look KY, et al: Cyclophosphamide and cisplatin compared with paclitaxel and cisplatin in patients with stage III and stage IV ovarian cancer. N Engl J Med 1996, 334:1-6.

11. Piccart MJ, Bertelsen K, James K, Cassidy J, Mangioni C, Simonsen E, et al: Randomized intergroup trial of cisplatin-paclitaxel versus cisplatincyclophosphamide in women with advanced epithelial ovarian cancer: three-year results. J Natl Cancer Inst 2000, 92:699-708.

12. Behrens BC, Hamilton TC, Masuda H, Grotzinger KR, Whang-Peng J, Louie KG, et al: Characterization of a cis-diamminedichloroplatinum(II)-resistant human ovarian cancer cell line and its use in evaluation of platinum analogues. Cancer Res 1987, 47:414-418.

13. Levin L, Hryniuk WM: Dose intensity analysis of chemotherapy regimens in ovarian carcinoma. J Clin Oncol 1987, 5:756-767.

14. Levin L, Simon R, Hryniuk W: Importance of multiagent chemotherapy regimens in ovarian carcinoma: dose intensity analysis. $J$ Natl Cancer Inst 1993, 85:1732-1742.

15. Dauplat J, Legros M, Condat P, Ferriere JP, Ben Ahmed S, Plagne R: Highdose melphalan and autologous bone marrow support for treatment of ovarian carcinoma with positive second-look operation. Gynecol Oncol 1987, 34:294-298.

16. Viens $P$, Maraninchi $D$, Legros M, Oberling F, Philip T, Herve $P$, et al: High dose melphalan and autologous marrow rescue in advanced epithelial ovarian carcinomas: a retrospective analysis of 35 patients treated in France. Bone Marrow Transplant 1990, 5:227-233.

17. Bertucci F, Viens P, Delpero JR, Bardou VJ, Faucher C, Houvenaeghel G, et al: High-dose melphalan-based chemotherapy and autologous stem cell transplantation after second look laparotomy in patients with chemosensitive advanced ovarian carcinoma: long-term results. Bone Marrow Transplant 2000, 26:61-67

18. Viret F, Bertucci F, Genre D, Gravis G, Chabannon C, Conte M, et al: Intensive sequential dose chemotherapy with stem cell support as first-line treatment in advanced ovarian carcinoma: a phase II study. Bone Marrow Transplant 2000, 30:879-884

19. Papadimitriou C, Dafni U, Anagnostopoulos A, Vlachos G, Voulgaris Z Rodolakis A, et al: High-dose melphalan and autologous stem cell transplantation as consolidation treatment in patients with chemosensitive ovarian cancer: results of a single-institution randomized trial. Bone Marrow Transplant 2008, 41:547-554

20. Möbus V, Wandt H, Frickhofen N, Bengala C, Champion K, Kimmig R, et al: Phase III trial of high-dose sequential chemotherapy with peripheral blood stem cell support compared with standard dose chemotherapy for first-line treatment of advanced ovarian cancer: intergroup trial of the AGO-Ovar/AIO and EBMT. J Clin Oncol 2007, 25:4187-4193.

21. Bertucci F, Tarpin C, Charafe-Jauffret E, Bardou VJ, Braud AC, Tallet A, et al: Multivariate analysis of survival in inflammatory breast cancer: impact of intensity of chemotherapy in multimodality treatment. Bone Marrow Transplant 2004, 33:913-920.

22. Viens P, Tarpin C, Roche H, Bertucci F: Systemic therapy of inflammatory breast cancer from high-dose chemotherapy to targeted therapies: the French experience. Cancer 2010, 116(11 Suppl):2829-2836.

23. Zander AR, Schmoor C, Kröger N, Krüger W, Möbus V, Frickhofen N, et al: Randomized trial of high-dose adjuvant chemotherapy with autologous hematopoietic stem-cell support versus standard-dose chemotherapy in breast cancer patients with 10 or more positive lymph nodes: overall survival after 6 years of follow-up. Ann Oncol 2008, 19:1082-1089.

24. Biron $P$, Durand M, Roché $H$, Delozier T, Battista C, Fargeot $P$, et al: Pegase 03: a prospective randomized phase III trial of FEC with or without high-dose thiotepa, cyclophosphamide and autologous stem cell transplantation in first-line treatment of metastatic breast cancer. Bone Marrow Transplant 2008, 41:555-562.

25. Berry DA, Ueno NT, Johnson MM, Lei X, Caputo J, Rodenhuis S, et al: High-dose chemotherapy with autologous stem-cell support as adjuvant therapy in breast cancer: overview of 15 randomized trials. J Clin Oncol 2011, 29:3214-3223.

26. Hartmann JT, Gauler T, Metzner B, Gerl A, Casper J, Rick O, et al: Phase I/II study of sequential dose-intensified ifosfamide, cisplatin, and etoposide plus paclitaxel as induction chemotherapy for poor prognosis germ cell tumors by the German testicular cancer study group. J Clin Oncol 2007, 25:742-5747.

27. Gonçalves A, Delva R, Fabbro M, Gladieff L, Lotz JP, Ferrero JM, et al: Post-operative sequential high-dose chemotherapy with haematopoietic stem cell support as front-line treatment in advanced ovarian cancer: a phase II multicentre study. Bone Marrow Transplant 2006, 37:651-659.

28. Viens P, Bertucci F, Gravis G, Camerlo J, Cowen D, Delpero JR, et al: Intensive chemotherapy with autologous stem cell transplantation in ovarian cancers: analysis of 67 patients treated at the Paoli-Calmettes Institute and a review of the literature. Bull Cancer 1997, 9:869-876.

29. Cure H, Battista C, Guastalla JP, Fabbro M, Tubiana-Mathieu N, Bourgeois H, et al: Phase III Randomized Trial of High-Dose Chemotherapy (HDC) and Peripheral Blood Stem Cell (PBSC) Support as Consolidation in Patients (pts) with Responsive Low-Burden Advanced Ovarian Cancer (AOC): Preliminary Results of a GINECO/ FNCLCC/ SFGM-TC Study. Proc Am SoC Clin Oncol 2001, 20(abstr 815).

30. Legros M, Dauplat J, Fleury J, Cure H, Suzanne F, Chassagne J, et al: High-dose chemotherapy with hematopoietic rescue in patients with stage III to IV ovarian cancer: long-term results. J Clin Oncol 1997, 15:1302-1308

31. Stiff PJ, Bayer R, Kerger C, Potkul RK, Malhotra D, Peace DJ, et al: High-dose chemotherapy with autologous transplantation for persistent/relapsed ovarian cancer: a multivariate analysis of survival for 100 consecutively treated patients. J Clin Oncol 1997, 15:13092-1317.

32. Stiff PJ, Shpall EJ, Liu PY, Wilczynski SP, Callander NS, Scudder SA, et al: Randomized Phase II trial of two high-dose chemotherapy regimens with stem cell transplantation for the treatment of advanced ovarian cancer in first remission or chemosensitive relapse: a Southwest Oncology Group study. Gynecol Oncol 2004, 94:98-106.

33. Pal T, Permuth-Wey J, Betts JA, Krischer JP, Fiorica J, Arango H, et al: BRCA1 and BRCA2 mutations account for a large proportion of ovarian carcinoma cases. Cancer 2005, 104:2807-2816.

34. Boyd J, Sonoda Y, Federici MG, Bogomolniy F, Rhei E, Maresco DL, et al: Clinicopathologic features of BRCA-linked and sporadic ovarian cancer. JAMA 2000, 283:2260-2265.

35. Vencken PM, Kriege M, Hoogwerf D, Beugelink S, van der Burg ME, Hooning MJ, et al: Chemosensitivity and outcome of BRCA1- and BRCA2-associated ovarian cancer patients after first-line chemotherapy compared with sporadic ovarian cancer patients. Ann Oncol 2011, 22:1346-1352.

36. Tan DS, Rothermundt C, Thomas K, Bancroft E, Eeles R, Shanley S, et al: "BRCAness" syndrome in ovarian cancer: a case-control study describing the clinical features and outcome of patients with epithelial ovarian cancer associated with BRCA1 and BRCA2 mutations. J Clin Oncol 2008, 26:5530-5536.

37. Konstantinopoulos PA, Spentzos D, Karlan BY, Taniguchi T, Fountzilas E, Francoeur N, et al: Gene expression profile of BRCAness that correlates with responsiveness to chemotherapy and with outcome in patients with epithelial ovarian cancer. J Clin Oncol 2010, 28:3555-3561. 
38. Bast RC Jr, Mills GB: Personalizing therapy for ovarian cancer: BRCAness and beyond. J Clin Oncol 2010, 28:3545-3548.

39. Fong PC, Boss DS, Yap TA, Tutt A, Wu P, Mergui-Roelvink M, et al: Inhibition of poly(ADP-ribose) polymerase in tumors from BRCA mutation carriers. N Engl J Med 2009, 361:123-134.

40. Fong PC, Yap TA, Boss DS, Carden CP, Mergui-Roelvink M, Gourley C, et al: Poly(ADP)-ribose polymerase inhibition: frequent durable responses in BRCA carrier ovarian cancer correlating with platinum-free interval. J Clin Oncol 2010, 28:2512-2519.

41. Audeh MW, Carmichael J, Penson RT, Friedlander M, Powell B, Bell-McGuinn KM, et al: Oral poly(ADP-ribose) polymerase inhibitor olaparib in patients with BRCA1 or BRCA2 mutations and recurrent ovarian cancer: a proof-of-concept trial. Lancet 2010, 376:245-251.

42. Gelmon KA, Hirte HW, Robidoux A, Tonkin KS, Tischkowitz M, Swenerton K, et al: Olaparib in patients with recurrent high-grade serous or poorly differentiated ovarian carcinoma or triple-negative breast cancer: a phase 2, multicentre, open-label, non-randomised study. Lancet Oncol 2011, 12:852-861.

43. Piccart MJ, Floquet A, Scarfone G, Willemse PH, Emerich J, Vergote I, et al: Intraperitoneal cisplatin versus no further treatment: 8-year results of EORTC 55875, a randomized phase III study in ovarian cancer patients with a pathologically complete remission after platinum-based intravenous chemotherapy. Int J Gynecol Cancer 2003, 13(Suppl 2):196-203.

44. Pecorelli S, Favalli G, Gadducci A, Katsaros D, Panici PB, Carpi A, et al: Phase III trial of observation versus six courses of paclitaxel in patients with advanced epithelial ovarian cancer in complete response after six courses of paclitaxel/platinum-based chemotherapy: final results of the After-6 protocol 1. J Clin Oncol 2009, 27:4642-4648.

45. Perren TJ, Swart AM, Pfisterer J, Ledermann JA, Pujade-Lauraine E, Kristensen G, et al: A phase 3 trial of bevacizumab in ovarian cancer. N Engl J Med 2011, 365:2484-96.

doi:10.1186/1756-9966-31-87

Cite this article as: Sabatier et al: Are there candidates for high-dose chemotherapy in ovarian carcinoma?. Journal of Experimental \& Clinical Cancer Research 2012 31:87.

\section{Submit your next manuscript to BioMed Central and take full advantage of:}

- Convenient online submission

- Thorough peer review

- No space constraints or color figure charges

- Immediate publication on acceptance

- Inclusion in PubMed, CAS, Scopus and Google Scholar

- Research which is freely available for redistribution 